\title{
Eggplant Peel Extract Cream
}

National Cancer Institute

\section{Source}

National Cancer Institute. Eggplant Peel Extract Cream. NCI Thesaurus. Code C162859.

A cream containing an extract from the skin of the vegetable Solanum melongena

(egg plant; S. melongena; aubergine; brinjal) containing high levels of bioactive

components, such as anthocyanins, with potential anti-oxidant, keratolytic, and

antineoplastic activities. Upon topical administration of the egg plant peel extract cream,

the active ing redients in the egg plant extract may exert antioxidant, anti-proliferative and protective effects on skin cells. 